\title{
Sharing Experiences between the Academy and Architecture Offices in Parametric Modeling and Digital Manufacturing
}

\author{
Janice de Freitas Pires \\ Universidade Federal de Pelotas | Brasil | janicefpires@gmail.com
}

Adriane Borda Almeida da Silva

Universidade Federal de Pelotas | Brasil | adribord@hotmail.com

Alexandre Berneira da Silva

Universidade Federal de Pelotas | Brasil | asberneira@gmail.com

Ramile da Silva Leandro

Universidade Federal de Pelotas | Brasil | ramileleandro@hotmail.com

\begin{abstract}
This paper presents the results of actions aimed at sharing experiences of recognition and appropriation of techniques of parametric design and digital fabrication with architectural offices, developed within the scope of an extension project. Such actions have invested in spreading a culture of using such techniques so that architecture professionals can help to envision applications together with the resolution of design problems in specific and local contexts. As a result, in addition to the students' own training in the subject in question, the participants in the actions were given an opportunity to reflect on the knowledge shared between academia and architecture professionals.
\end{abstract}

Keywords: Parametric modeling; Digital fabrication; Architecture offices; Extension activities.

\section{INTRODUÇÃO}

Nos últimos anos, junto ao processo formativo de arquitetura, vários esforços têm sido empreendidos para a apropriação de práticas que conectam o desenho paramétrico com a fabricação digital (Celani e Sedrez, 2018). Entretanto, ainda é difícil perceber os efeitos do reconhecimento e/ou reflexão sobre o uso e/ou pertinência de uso destas práticas para além dos espaços acadêmicos.

Particularmente, junto ao contexto em que se insere este trabalho, as práticas projetuais, estabelecidas em escritórios, avançam para o uso, por exemplo, da parametrização dirigida ao gerenciamento da informação, mas ainda sem estarem permeadas por processos generativos ou também envolvendo a fabricação digital.

Esta percepção é conformada por meio do acompanhamento da prática de estágios de estudantes de arquitetura em escritórios e empresas de arquitetura, design e engenharia locais, sem, contudo, haver dados já sistematizados para quantificar algum percentual sobre o cenário do entorno imediato quanto a este avanço. De qualquer maneira, ainda existe uma distância entre os estudos teóricos, acadêmicos e exploratórios, sobre o tema desenho paramétrico e fabricação digital e a realidade de aplicação ao campo da produção de arquitetura. Junto ao contexto formativo local, em termos curriculares, é muito recente a inclusão destas técnicas (a partir de 2012) e isto tem ocorrido em disciplinas introdutórias de representação. Desta maneira, os profissionais advindos deste contexto vivenciaram problemas didáticos, principalmente no campo da geometria, que para alguns podem até ter se perdido no tempo pela descontinuidade de investimento em disciplinas de projeto propriamente ditas. Mesmo que os exercícios, de introdução ao desenho paramétrico, estivessem acompanhados de um discurso para situar a abrangência em todo campo da arquitetura, as práticas possíveis junto às disciplinas de início de curso envolvem essencialmente parâmetros geométricos.

A partir de Llach e Burbano (2020) tem-se uma provocação importante sobre como contextos acadêmicos e profissionais reagem frente ao avanço da ciência, tecnologia e inovação, e como este avanço é um processo complexo, especialmente observando enfoques de "transferência entre um Norte desenvolvido e um Sul subdesenvolvido o qual persegue uma sempre evasiva modernidade digital." (tradução nossa, p.15). Os referidos autores reconhecem um repertório de estudos, de análises bibliométricas, que permitem observar como tem ocorrido a disseminação do emprego de técnicas de desenho paramétrico e também da difusão do que se configuram hoje como FABLABs nos contextos latinoamericanos. Entretanto, atentam para a necessidade de compreender os "detalhes, matizes e pontos de inflexão" de diferentes realidades que podem "desestabilizar a universalidade e centralidade dos sistemas tecnológicos". 
Argumentam sobre a necessidade de observar as "especificidades histórica, material e estética dos sistemas informáticos" para reconsiderar o "enfoque de uma computação universal" para um enfoque de "computações plurais e situadas" (p.17).

Entende-se que é no espaço da extensão universitária onde é possível dar eco a estes questionamentos, ultrapassando o propósito de "difusão" de um conhecimento novo para a compreensão da pertinência de sua apropriação e significação. Nesta direção, o projeto PRO_ACORDA: PROmoção de Ações e de COmpartilhamento de experiências de empreendedorismo e inovação na área de Representação (fabricação digital e desenho paramétrico) para o Projeto em Design e Arquitetura, desenvolvido junto ao Grupo de Estudos para o Ensino/aprendizagem de Gráfica Digital (GEGRADI), da Faculdade de Arquitetura e Urbanismo (FAURB) da Universidade Federal de Pelotas(UFPel), tem o objetivo de estabelecer um espaço de aprendizagem compartilhada, entre estudantes e profissionais, sobre fabricação digital e desenho paramétrico que hoje permeiam a prática projetual e construtiva de arquitetura e design.

A abordagem do desenho paramétrico possibilita atribuir relacionamentos entre os elementos de um projeto, podendo este ser controlável por meio da modelagem associativa e da variação de parâmetros (Schumacher, 2018). Este método tem o propósito de desencadear um conjunto de soluções que respondam a tais relações, gerando formas emergentes, com potencial generativo (Kolarevic, 2003).

O PRO_ACORDA visa uma aproximação entre os polos da teoria (estudo de referenciais de arquitetura paramétrica e fabricação digital) e da prática dessas ações (o fazer através de oficinas e discussões com escritórios de arquitetura). Desta maneira, busca-se intensificar as conexões entre o 'saber' e o 'saber-fazer', nos termos da "Teoria Antropológica da Didática" (Chevallard, 1999), a qual estuda a gênese da atividade humana a partir da noção estruturada do saber. Este Projeto extensionista tem configurado ações formativas, informativas e colaborativas, entre a academia e profissionais de escritórios de arquitetura e design, para constituir uma dinâmica de interação que promove a atualização, avaliação e possível validação do uso das técnicas de desenho paramétrico e de fabricação digital. O projeto trata de investir na promoção de momentos que auxiliem a construção de uma cultura de reconhecimento de tais saberes em ambos os contextos: acadêmico e de escritórios de arquitetura.

Para a academia o Projeto se configura como um espaço que possibilita vivenciar momentos de produção, com propósitos inovadores, imersos em um contexto profissional, como um escritório de arquitetura ou um estúdio de design. Para o contexto profissional, uma oportunidade de contrapor as práticas já estabelecidas de projeto com as de desenho paramétrico e fabricação digital, ainda com caráter inovador, observando a pertinência em realizar esforços para uma atualização e/ou exploração das referidas práticas. Para ambos, representa uma forma de ensino e aprendizagem que nasce da interação entre as duas esferas do conhecimento, como descrito em Chevallard (1999) de entender as técnicas projetuais abordadas dentro da instituição acadêmica e transforma-las, adapta-las, repensa-las a partir da vivencia fora de tal ambiente, no da prática diária da teoria. Igualmente tem a intenção de promover a reflexão dentro desses escritórios atuando na identificação de problemas apropriados ao uso de tais tecnologias, atribuindo um significado efetivo. Por exemplo, para a dinâmica de um escritório de arquitetura, busca transpor um problema que no momento da ação está sendo resolvido com as técnicas tradicionais de projeto e promover um processo aberto, dialogado, em que o projetista do lugar problematize/vivencie a lógica da transposição para o desenho paramétrico. Isto pode permitir ao profissional compreender que os resultados, com este método de projeto, se referem a um conjunto de soluções que pode ser replicado a outros problemas similares, de maneira automatizada, a parir de um raciocínio projetual, representado por meio de um sistema de projeto (programação visual), mantendo o caráter inovador como pressupõe o processo projetual de arquitetura.

Neste trabalho apresentam-se os resultados das ações promovidas junto a escritórios de arquitetura, ocorridas no primeiro semestre de 2019, buscando-se apresentar algumas reflexões concernentes ao dialogo travado entre "teoria e prática", entre "saber" e "saber fazer", vivenciado a partir de atividades diferenciadas para a prática de arquitetura de contextos específicos e situados.

\section{METODOLOGIA}

Para atingir o objetivo proposto o projeto está estruturado a partir de três tipos de ações:

1. Promoção de ações formativas: Em formato de cursos de extensão (educação continuada), para abordar o conceito e procedimentos de desenho paramétrico e fabricação digital, incluindo especialmente as tecnologias envolvidas com exercícios práticos. $\mathrm{O}$ público alvo referese aos estudantes, docentes e profissionais de arquitetura e design. Nessa etapa, os envolvidos têm a oportunidade de se familiarizarem com as técnicas apresentadas, assim como de proporem suas ideias, demostrarem seus interesses e criarem uma identidade enquanto grupo que, a partir da troca de experiências e saberes, constrói bases para serem compartilhadas fora do ambiente acadêmico.

\section{Promoção de ações informativas}

Em formato de eventos, junto aos escritórios de arquitetura, para compartilhar os casos estudados pela equipe do PRO_ACORDA, de projetos e obras de arquitetura, que envolveram 0 uso do conceito e procedimentos de desenho paramétrico e fabricação digital. Os casos estudados, na medida do possível, passam a ser selecionados a partir do diálogo com os escritórios, utilizando-se também da aplicação de um instrumento de avaliação (questionário) para compreender as aplicações de interesse.

3. Promoção de ações in loco: Estas ações serão configuradas a partir da tentativa de imersão de especialistas/estudantes/estagiários em desenho paramétrico e fabricação digital nos escritórios de arquitetura e design. Por meio de parcerias, a ação busca 
identificar problemas cotidianos de trabalho que possam ser incrementados em seu potencial criativo ou de automatização, otimização e racionalização de processos produtivos. Inclui o esforço de identificar casos que ilustrem as vantagens de uso dos conceitos e procedimentos em questão. Na medida do possível, o processo de seleção dos casos, para além das oportunidades, tentará diversificar os tipos de aplicações, desde o design de elementos de fachadas, de mobiliário, de interiores, de paisagismo, abarcando assim as diferentes escalas de projeto, do detalhe ao urbano.

Todas as ações são promovidas envolvendo uma equipe, constituída de ex-bolsistas de iniciação científica e de extensão, os quais investiram em uma formação especializada nas tecnologias em questão e estão dispostos a adquirir uma capacitação para o empreendedorismo e a inovação a partir da aplicação destes conhecimentos junto ao contexto profissional de arquitetura e design.

Para os dois semestres de 2019, as ações foram projetadas e executadas a partir das seguintes etapas:

- Revisão bibliográfica: a revisão tratou de compreender o conceito de design paramétrico associado à fabricação digital a partir de Celani e Sedrez (2018) e Woodburry (2010) e, principalmente, buscou identificar casos de projetos de arquitetura apoiados na associação destes conceitos, a partir de Burry \& Burry (2010).

- Seleção e estudo dos casos de arquitetura ilustrativos das aplicações em desenho paramétrico e fabricação digital;

- Apropriação de técnicas de desenho paramétrico e de fabricação digital;

- Execução de protótipos de exemplificação;

- Estruturação de um material didático como suporte à ação;

- Aplicação da ação nos escritórios de arquitetura;

- Elaboração e aplicação de um instrumento de avaliação das ações.

\section{RESULTADOS}

A seguir apresentam-se os principais resultados do projeto no ano de 2019.

Desenvolvimento das Ações do tipo 1: Como ação formativa, em maio de 2019, foram desenvolvidos momentos de formação aos estudantes bolsistas e colaboradores do projeto, visando um primeiro contato com as técnicas de modelagem paramétrica e fabricação digital, a partir de oficinas de geração de geometrias empregadas na arquitetura contemporânea. Em tal etapa do projeto, o grupo teve a oportunidade, através de novos conhecimentos, de entender as facilidades e dificuldades de tais ferramentas, assim como de explorar e propor o desenvolvimento de estudos para a configuração de objetos do mobiliário, com tais técnicas.
Desenvolvimento das Ações do tipo 2: Para as ações informativas do primeiro semestre de 2019 foram adotados como objetos de estudo uma obra de arquitetura considerada significativa em relação ao uso da abordagem do desenho paramétrico no processo de projeto, o Museu Louvre de Abu Dhabi, do arquiteto Jean Nouvel (Figura 1), e mobiliários projetados parametricamente e produzidos por fabricação digital.

A partir da análise da obra foram explicitados os aspectos conceituais e generativos de projeto, os quais incluíram a cultura local, a geometria e a estrutura, articulados com o desempenho lumínico e térmico. Estes aspectos foram avaliados pelo escritório que desenvolveu o projeto por intermédio de técnicas paramétricas de modelagem e de fabricação digital.

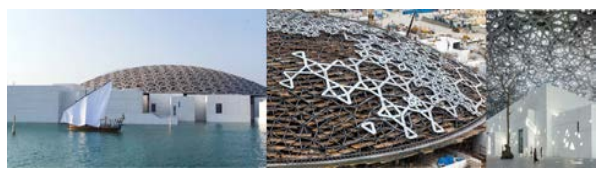

Figura1: Museu do Louvre de Jean Nouvel. Fonte das imagens: https:// habitarsolucoes.com/2018/10/24/conheca-o-louvre-abudhabi-um-verdadeiro-refugio-de-luz-sob-uma-linda-e-complicadaestrutura-geodesica/

Por meio do estudo de exemplos de mobiliários concebidos parametricamente a partir da técnica de planos seriados e materializados por corte a laser em materiais em chapa e da apropriação das técnicas de modelagem paramétrica e de fabricação digital, desenvolveram-se protótipos de apoio às ações. Previamente ao processo de execução dos protótipos de exemplificação, foram reconhecidos os estudos de antropometria de Panero e Zelnik (2014).

$\mathrm{Na}$ sequência, foi projetado e modelado um banco paramétrico com geometria estruturada por curvas ergonômicas (Pronk, 2003), gerando-se uma forma flexível (Figura 2).

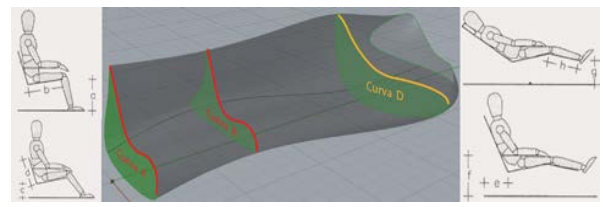

Figura 2: Banco modelado com o uso de curvas ergonômicas. Fonte das imagens: estudo de ergonomia por Pronk (2003) e modelagem por elaboração dos autores.

Os mobiliários foram executados por corte a laser, e montados manualmente por encaixe de suas partes seccionadas (Figura 3); O desenho do padrão de perfurações da cúpula do Museu do Louvre também foi executado, para ilustrar o efeito de "chuva de luz" que é produzido ao se sobrepor várias camadas e escalas de tal desenho (Figura 4). 


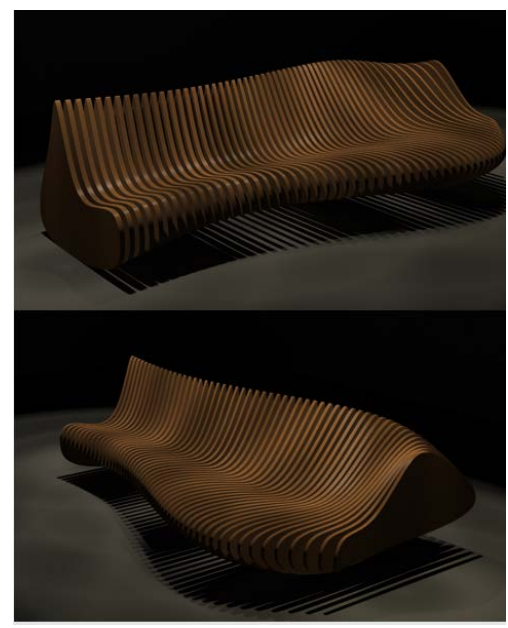

Figura 3: Protótipo de um banco parametrizado desenvolvido em corte a laser. Fonte das imagens: autores.

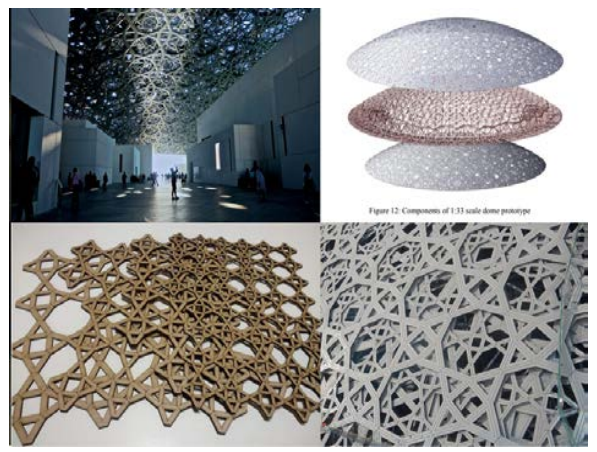

Figura 4: Padrão da cobertura do Museu do Louvre, desenvolvidos em corte a laser. Fonte das imagens: autores e http://docgelo.com/2017/12/02/louvre-abu-dhabi-and-my-favoritemasterpieces/ e https://www.detail-online.com/artikel/louvre-abudhabi-a-huge-dome-of-85-puzzle-pieces-29805/

Os materiais de apoio desenvolvidos trataram de tal análise do Museu do Louvre, contendo a história, o contexto e o conceito do projeto e trouxeram os exemplos de mobiliário, tal como o banco concebido e fabricado pelos estudantes participantes das ações. Estes últimos podem ser compreendidos como exemplos potenciais para uma aproximação com o contexto imediato, em função de sua aplicabilidade de execução na região.

Foi realizado o mesmo tipo de ação duas vezes, com a mesma equipe de tres estudantes de arquitetura do terceiro semestre em dois escritórios locais (ação 1 e 2). Ambos os escritórios trabalham simultaneamente com projetos de arquitetura e de interiores, coordenados por profissionais arquitetos, em sua maioria advindos da FAURB/UFPel, em um período em que estes saberes ainda não eram veiculados no currículo. Entretanto, um destes escritórios (da ação 2) esteve representado por uma única profissional arquiteta que já possuia um conhecimento prévio, tanto em desenho paramétrico como em fabricação digital, por decorrência de uma formação como especialista na área de gráfica digital, obtida neste mesmo contexto institucional. O outro escritório participou da ação 1 com uma equipe formada por seis arquitetas.

O tipo de interação utilizado para as duas ações foi por apresentação oral auxiliada por mídia digital em forma de slides, sendo dividida em três partes distintas: - a primeira incluiu uma introdução ao desenho paramétrico e a explicação dos estudos de caso; a segunda apresentou os protótipos executados para a ação; e, a terceira, caracterizou-se por um espaço de trocas de informações (Figuras 5 e 6 )

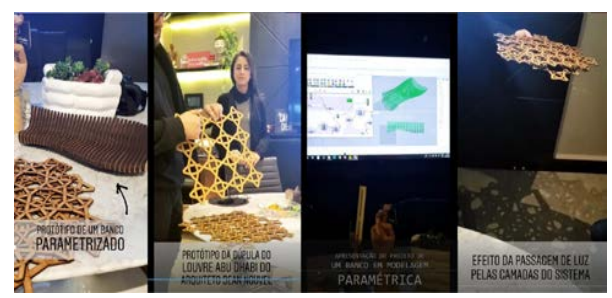

Figura 5: Aplicação da ação 1, em escritório de arquitetura, no primeiro semestre de 2019. Fonte: Autores.

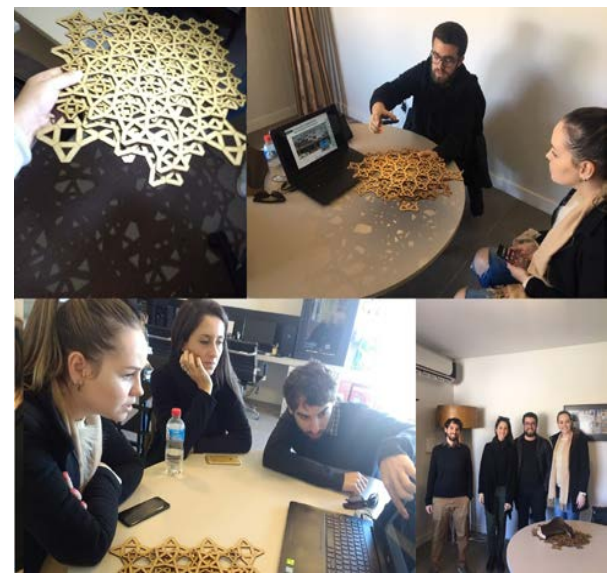

Figura 6: Aplicação da ação 2, em escritório de arquitetura, no primeiro semestre de 2019. Fonte: Autores.

Para desenvolver o instrumento de avaliação, foi estruturado um questionário on-line, contendo perguntas que buscaram identificar os aspectos positivos e negativos das ações, e mensurar seus impacto, assim como a autovaloração do conhecimento prévio acerca do desenho paramétrico. Na Tabela 1 são registradas as respostas a quatro perguntas do questionário aplicado aos dois escritórios.

Tabela 1 - Respostas a quatro perguntas do questionário aplicado nos dois escritórios. Fonte: Autores.

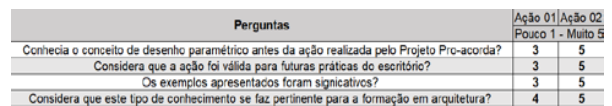

Previamente ao contato com os escritórios, os estudantes criaram um folder de apresentação do projeto e da equipe 
(Figura 7), contendo uma descrição dos objetos de análise envolvidos no material de apoio às ações informativas. Considerou-se que este folder divulgado junto ao contato inicial por e-mail poderia despertar o interesse dos escritórios devido ao seu conteúdo visual e ilustrativo do material e dos propósitos do grupo com as ações.

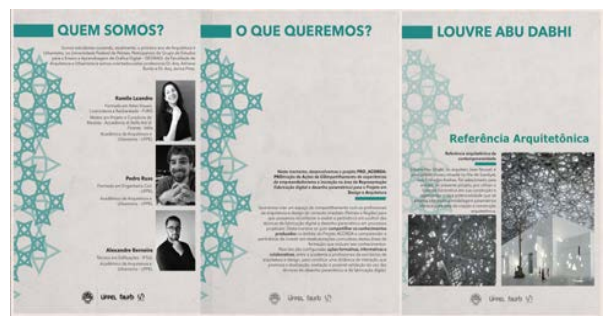

Figura 7: Recortes do folder de apresentação aos escritórios de arquitetura, desenvolvido pelo grupo de estudantes do projeto, no primeiro semestre de 2019. Fonte: Autores.

Os profissionais envolvidos na primeira ação pouco conheciam o conceito de desenho paramétrico, fato confirmado pela resposta dada no questionário. Isto exigiu explanar sobre as noções básicas relativas a este. Já em relação à segunda ação, pelo fato de a profissional envolvida ter conhecimento prévio sobre o assunto, o que também foi confirmado no questionário aplicado, houve maior interesse e troca sobre os casos de projeto estudados, evidenciando 0 entendimento das potencialidades para arquitetura.

Em relação à forma de interação com os profissionais de arquitetura, identificou-se que, no primeiro escritório, devido à forma expositiva, houve uma interação menor em relação à segunda ação, que ocorreu de modo mais espontâneo e interativo. Isto se deveu a ter havido uma discussão direta e dialogada com o profissional de arquitetura, a cerca de cada tema apresentado, tendo-se uma troca mais qualitativa de experiências com os estudantes promotores da ação.

Apesar das respostas do questionário apontarem para a relevância do Projeto quanto ao aspecto da disseminação do conhecimento acerca do desenho paramétrico, entende-se que este momento inicial de desenvolvimento das ações junto aos escritórios trouxe ganhos específicos para o contexto acadêmico. Contudo, os profissionais ainda não parecem ter clareza em como aplicar tal abordagem em seus projetos no dia a dia, o que traz a reflexão também para o contexto acadêmico. A partir de uma imersão continuada dos estudantes no contexto profissional, poderia se detectar as necessidades dos profissionais e exemplificar o potencial de tais técnicas na resolução dos problemas cotidianos de arquitetura, instigando-os para a sua adoção.

Sendo assim, os principais resultados são a avaliação dos escritórios quanto à adequação das ações, a inicialização de uma coleção de casos de estudo de desenho paramétrico no projeto de arquitetura, a formação dos estudantes no tema e a difusão da cultura do desenho paramétrico nos escritórios locais.
Ainda como resultados destas ações relativamente às metas do projeto, considera-se que foi possível: - Ampliar o reconhecimento do uso do desenho paramétrico e fabricação digital como método projetual no contexto dos escritórios de Arquitetura e Design na cidade de Pelotas e região; Capacitar profissionais de arquitetura e design para identificar problemas em que o desenho paramétrico e a fabricação digital possam otimizar; e qualificar o processo projetual.

As ações formativas e informativas constituíram-se como parte fundamental no processo de apropriação das tecnologias digitais propostas pelo projeto. Isso porque, é através da troca entre professores, estudantes e profissionais que atuam no mercado de arquitetura local que o saber teórico é confrontado, experimentado. Nessa fusão de conhecimentos é que o processo de ensino e aprendizagem é repensado e aprimorado.

Destaca-se também a adequação dos objetos de estudo escolhidos em relação aos aspectos tecnológicos (discuros sobre a técnica) destacando-se a potencia que a parametria e a fabricação digital possuem para a resolução de classes de problemas: a primeira, problemas tais como os de sombreametno de fachadas ou de interiores, que foi exemplificado pela técnica de chuva de luz; a segunda, para a criação e customização de mobiliários. Os dois casos selecionados tentaram representar técnicas potentes para a resolução de problemas.

Também foram alcançados parcialmente os seguintes resultados esperados previstos no projeto: A estruturação, formatação e disponibilização de processos formativos nas modalidades presencial e a distância; Identificação do repertório de problemas cotidianos da prática projetual junto ao contexto estudado apropriado para o uso das tecnologias em questão; Qualificação da equipe envolvida para a docência e consultoria em desenho paramétrico e fabricação digital aplicados ao processo projetual de arquitetura e design; Intensificação da interação do contexto profissional com o contexto acadêmico.

\section{DISCUSSÃO}

A relevância das ações de 2019 pode ser compreendida a partir de seus impactos na formação profissional, na aquisição de conteúdos e habilidades, na compreensão da realidade social e na contribuição para o desenvolvimento do projeto. Estes impactos referem-se a (o):

- Na formação profissional. A possibilidade de conhecer e experimentar técnicas e processos de projeto que se constituem como o modo de produção da arquitetura de hoje nos contextos profissionais em que o projeto é voltado aos problemas contemporâneos da arquitetura.

- Na aquisição de conteúdos e habilidades. Conceitos referentes ao projeto paramétrico e as técnicas para o seu desenvolvimento, possibitando a aquisição de habilidades para identificar soluções de projeto potenciais ao emprego de tais técnicas e para estruturar sistemas que abarquem tais problemas projetuais. 
- Na compreensão da realidade social. A atribuição de novos papéis ao arquiteto e ao usuário da arquitetura, principalmente em relação ao alcance de edifícios sustentáveis ao longo de seu ciclo de vida e a participação mais consciente do usuário nas decisões projetuais.

- Na contribuição para o desenvolvimento do projeto. Incremento na exemplificação de abordagens de projeto para a geração de uma gama de soluções alternativas, a customização de projetos e produtos e o processo de avaliação de desempenho, simultâneo ao ato de projetar. O processo de compartilhamento de experiências com os escritórios locais forneceu subsídios e diretrizes para as ações que seguirão no projeto.

Pelo fato de as ações desenvolvidas até o momento terem tido maior receptividade em relação à aplicação da arquitetura de interiores (mobiliário), considera-se que o projeto deva ter continuidade a partir da busca por exemplos com maior aplicabilidade no contexto local, o que poderá facilitar a apropriação de tais técnicas pelos profissionais de arquitetura. As próximas ações também enfocarão na identificação dos problemas cotidianos dos escritórios que possam se valer das potencialidades de tais técnicas.

As experiências aqui relatadas têm seus impactos na continuidade do projeto, essencialmente quanto à identificação da necessidade de se desenvolverem atividades conjuntas com os escritórios de arquitetura, no sentido de que seus integrantes possam pensar, propor e operar, eles próprios, a adaptação de seus problemas as teorias, técnicas e tecnologias fundamentadas no projeto paramétrico e na fabricação digital, configurando o seu próprio 'saber-fazer' tecnológico.

Estudos têm sido empreendidos no sentido de compreender como a apropriação de tais tecnologias por grupos sociais tem se efetivado em vários países, principalmente na América Latina, tal como em Scheeren e Sperling (2018). Para os autores, o incremento da produção relacionada às condições específicas de cada região e que representam fatores culturais voltados à resolução de problemas em comum, com novas formas de trabalho e participação, tem sido peça chave para tal efetivação. A ideia, segundo os mesmos autores, seria de não nos limitarmos a simples transferência de tecnologias pré-concebidas, para que não se limite as condições de apropriação tecnológica. Os autores consideram que, em vez de copiar saberes e técnicas, a ideia de "reaplicação" é colocada, quando o conhecimento e a tecnologia existentes são ajustados às particularidades de cada contexto, em que a noção de tecnologia se estabelece como resultado da ação de atores sociais e decisões coletivas. No entanto, considera-se que iniciar o compartilhamento de experiências em desenho paramétrico e fabricação digital, no nível informativo e formativo, a partir de exemplificações das tecnologias e processos pré-concebidos e importados de outros contextos sociais, culturais e econômicos, possa auxiliar na disseminação e transposição de tal conhecimento para que ele possa ser adaptado e reconfigurado às condições locais e regionais.
Estes princípios devem então permear as experiências a serem desenvolvidas no futuro do projeto em questão, para que se possam alcançar práticas integradoras e conscientes, emergidas no contexto dos próprios escritórios de arquitetura mediante trocas de conhecimento com os acadêmicos e professores envolvidos.

Outro aspecto a se levar em conta é o espaço que a extensão oferece em oportunizar a troca entre os contextos profissional e educativo, podendo-se refletir do mesmo modo que Llach e Burbano (2020) quando se referem aos polos sul e norte, este último como produtor e exportador de tecnologias e o primeiro como receptor e importador, atentando-se para a necessidade de que os dois polos andem juntos, avaliando e acelerando o processo de reconhecimento dos avanços tecnológicos, em relação à pertinência de estarem permeando tanto as práticas didáticas como profissionais locais. Isto é importante para que nem a academia e nem o contexto profissional tenham posturas de transferência de tais saberes e tecnologias, mas sim exista uma retroalimentação entre os dois contextos, tendo a academia uma postura atenta às expressões locais do uso da tecnologia, atenta aos sujeitos de um entorno específico, buscando fazer visível outras maneiras de inovação e criatividade, sem que haja a expectativa de um enquadramento em padrões tecnopedagógicos acadêmicos ou importados (Llach e Burbano, 2020, p.14).

\section{REFERÊNCIAS}

Burry, J.; Burry, M. (2010). The New Mathematics of Architecture. London: Thames e Hudson.

Celani, G.; Sedrez, M (2018). Arquitetura Contemporânea e Automação. Prática e Reflexão. São Paulo: ProBooks Editora.

Chevallard, Y. (1999). El Análisis de las Prácticas Docentes en la Teoría Antropológica de Lo Didáctico. Recherches en Didactique de Mathématiques, Grenoble, 19(2), 221266, (Traducción de Ricardo Barroso, Universidad de Sevilla). $\quad$ Retrieved from http://www.aloj.us.es/rbarroso/Pruebas/CHEVALLARD.PDF

Kolarevic, B (2003). Architecture in the Digital Age: Design and Manufacturing. New York: Spon Press.

Llach, Daniel Cardoso y Burbano, Andrés. «Other Computations: Digital Technologies for Architecture from the Global South» Dearq 6-21. DOI: https://doi.org/10.18389/dearq27.2020.01

Panero, J.; Zelnik, M. (2014). Dimensionamento humano para espaços interiores. São Paulo: Gustavo Gili.

Pronk, E. (2003). Dimensionamento em Arquitetura. $7^{a}$. ed. João Pessoa: Editora Universitária.

Scheeren, R.; Sperling, D. M. (2018). Technological appropriation and socio-technical adequacy in South America: applications of digital fabrication in architecture and design. In: 22th Conference of the Iberoamerican Society of Digital Graphics. $07|08| 09 \mid$ nov|2018, p. 1-8.

Schumacher, P. (2019). The Progress of Geometry as Design Resource. Log, Summer, Londres, 2018. Retrieved from https://www.patrikschumacher.com/index.htm

Woodburry, R. (2010). Elements of Parametric Design. London: Routledge. 